\title{
Ultraviolet Imaging Techniques for Off-Line Condition Monitoring of Power System Equipment
}

\author{
Khawla Saeed Salim Al- \\ Khawaldi \\ Ohood Khamis Suwaid Al- \\ Maqbali \\ Fatema Khamis Rashid Al \\ Maamari \\ Bashayar Saif Said Al Khawaldi \\ Murali Krishna Boddu
}

\begin{abstract}
By using appropriate method to detect the functioning state of electrical equipment is always significantly more concerned with operational and economic point of view. With invention of the instruments which can capture images at Ultraviolet and infrared wavelength gives the required information for perceiving condition of the particular power system equipment with contactless measurement of parameters which leads the system to abnormal condition. Thermal, Corona images are those of such kind will be useful for the offline monitoring of the complex power system equipment where human cannot go and observe the actual status while system is under energized state. The equipment's mainly Power transformer, insulators, Circuit breakers, transmission line connection of power system are to be examined correctly. Thermal Imaging mainly gives the temperature raise of the component of the equipment and from that data is useful in analyzing the reasons and process for scheduled preservation before the disorder of the system. The corona discharge will cause the waste of power energy, radio interference, audible noise, insulation aging, and these defects are great threats to the safety and stability of electrical equipment. The different corona discharge defect part of high voltage electrical equipment is Listed such as the grading ring, drop wire, jumper and over line, spacing rods, tube bus end and connecting joint. While the photon numbers of corona discharge under different defects are measured by the ultraviolet imager called as corona image. The analysis is conducted for a $33 \mathrm{KV} / 11 \mathrm{KV}$ primary substation of a Distribution system along with secondary transmission line for thermal and Corona imaging. Infra-red Thermal camera and Ultraviolet Corona camera are used for the taking images at the substation. Thus, obtained data is compared with respective international standards for taking appropriate schedule for maintenance or clearance of the effected equipment at the earliest time possible to get the consumer with uninterruptable power supply.
\end{abstract}

\section{Introduction}

The Equipment in the power system will play an important role in the operation of the power system. The healthy condition of each of its is more important for the successful and wellmaintained operation of Power transfer from generating station to the consumer end. The advancement of condition monitoring technology various equipment and its healthy condition can be observed with non-contact and nondestructive manner. Infra-red imaging and Ultraviolet imaging are of such kind to assess the behavior of equipment under energized state.

The above-mentioned techniques will give the images any equipment on live system. The data pertaining to the images like temperature difference, Proton number will be used for the actions to be taken in order to estimate the situation at that point to observe the state of equipment. In order 
to take a specified action for the problem identified should be followed according to the specified international standards. As mentioned in the standard the equipment condition can be monitored with appropriate care. In this paper the above-mentioned techniques were

implemented at a $33 \mathrm{KV} / 11 \mathrm{KV}$ primary substation to view the status of certain important equipment like detection of fittings and conductors overheating, loose conductor connector, overheating fault of bolt line in cable outlet, overheating fault of conductor connectors will be done with infrared imaging and Degradation of Polymer Insulators, RFI, TVI and audio noise sources, Wrong design and improper installation are done with corona imaging. The images obtained will have to be used for analyzing the exact situation with respect to standard followed for the successful operation. The following sections will explain the detailed explanation of the thermal and corona imaging methods to view the power system equipment under safe operation in order to get lower downtime of the and more positive public perception. The main advantages of ultraviolet imaging techniques are, it does not have to contact the detected target, remote testing and remote measurement facility, the response time of infrared detection systems is counted in microseconds or milliseconds.

\section{Infrared(IR) Imaging Technique}

This section will explain infrared imaging popularly known as thermal imaging. It records the intensity of radiation in the infrared part of the electromagnetic spectrum and converts it to a visible image. mainly used Domestic installations to be testing inside complex industrial-based systems by which testing electrical systems for component damage, excessive heat and for ensuring overall system efficiency.
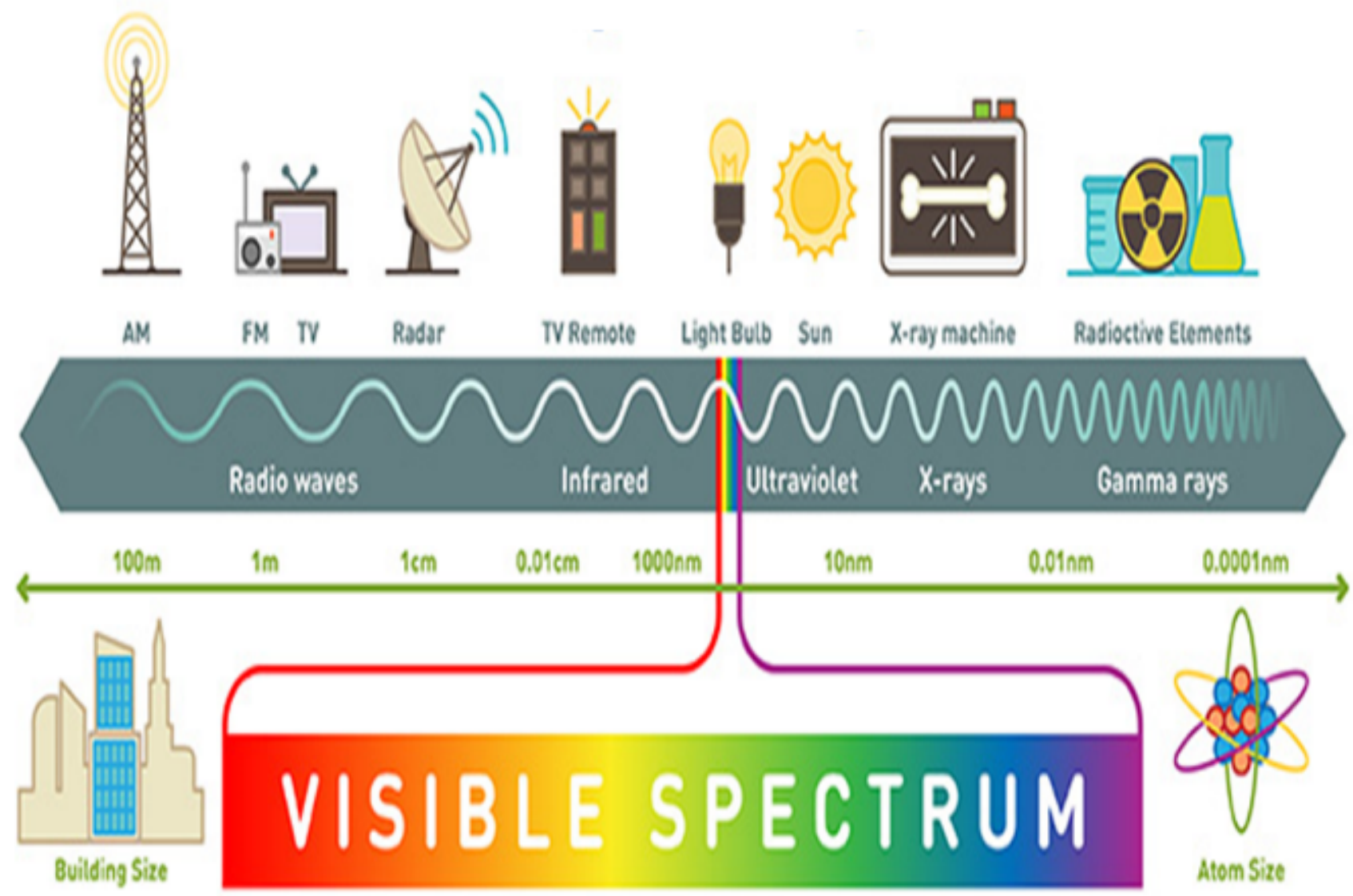

Figure 1. The Electromagnetic Spectrum. 


\section{Ultraviolet (UV)Imaging Techniques}

This section will explain about ultraviolet imaging popularly known as corona imaging. The corona is Ionization of a fluid (air) surrounding a conductor. This phenomenon occurs when the potential gradient (strength of the electric field) exceeds a threshold value, but conditions are insufficient to cause complete electrical breakdown or arcing. The ionization process generates, UV light, radio frequency and wide spectrum sound energy, including both audible and ultrasonic components.

The basic comparison of the both above mentioned techniques as follows

\begin{tabular}{|l|l|l|}
\hline Item & Ultraviolet Detection & Infrared Detection \\
\hline Waveband & $0.25-0.28 \mu \mathrm{m}$ & $8-14 \mu \mathrm{m}$ \\
\hline area of detection & Ultraviolet radiation & Infrared radiation \\
\hline Detection objects & fault related to corona & fault related to heating \\
\hline The sunlight interference & No & Yes \\
\hline The influence of weather & $\begin{array}{l}\text { In high humidity with low air pressure, } \\
\text { can be observed easily }\end{array}$ & High temperatures can easily interfere \\
\hline The range of detection faults & $\begin{array}{l}\text { Incipient equipment fault can be } \\
\text { detected }\end{array}$ & $\begin{array}{l}\text { Subsequent equipment faults are usually } \\
\text { detected }\end{array}$ \\
\hline
\end{tabular}

Table 1. Comparison of UV and IR Detection.

\section{Experimental Procedures}

\section{Study site}

The UV and IR detection of Power System Equipment faults can be done at a local 33KV/11KV primary distribution substation. The equipment selected for the taking images are IR camera and UV imaging Camera. These two devices can take the image of the equipment where human naked eye can not detect the fault caused by both temperature and corona.

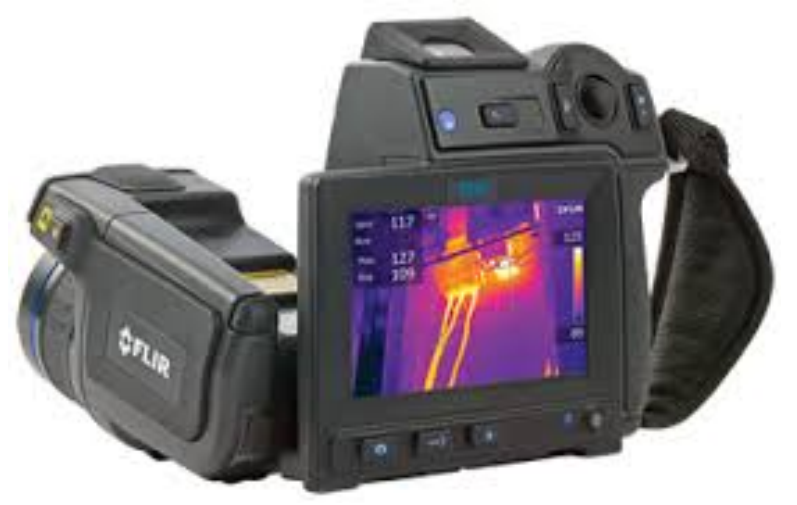

Figure 2. Thermal Imaging Camera (FLIR). 


\section{Journal of Student Research}

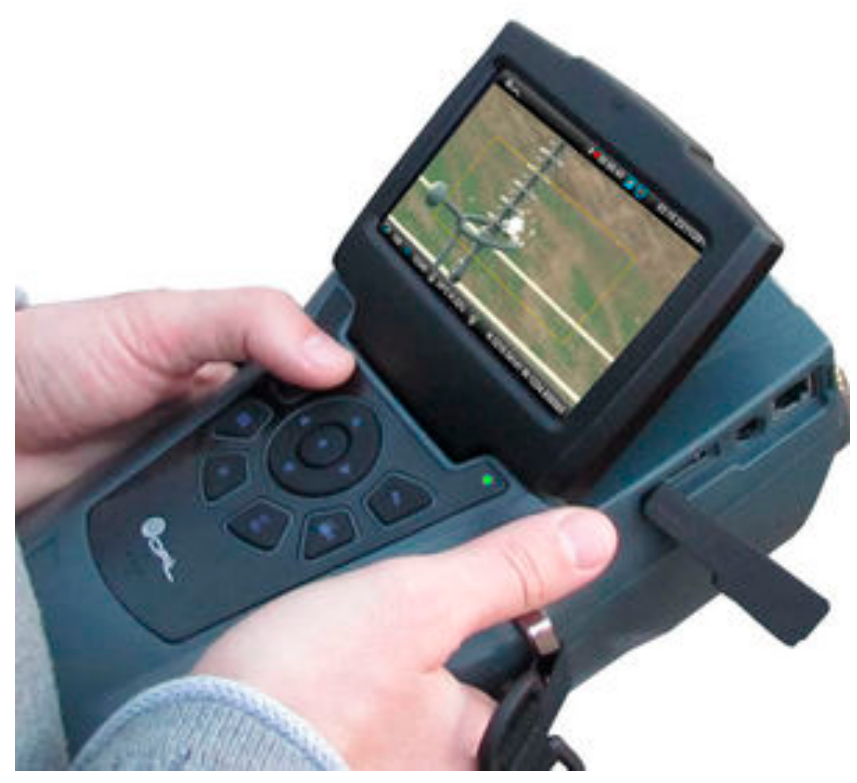

Figure 3. Corona Camera (Coro@Cam)

\section{Sample collection}

For thermal imaging the images were taken for normal and thermal for the following Equipment's like Insulator Diagnostics in Substations, Inspect SF6 Circuit Breakers, Connections in Electrical Transmission, Load Tap Changers (LTC).

The corona images are taken at Degradation of Polymer Insulators, RFI, TVI and audio noise sources, Wrong design and improper installation, Contamination due to dust, Cracked porcelain Insulators, Rust on Caps and Pins of an Insulators.

\section{Results}

\section{Thermal Imaging of Equipment.}

\section{(i) Insulator Diagnostics in Substations}

When an insulator fails, it may cause a widespread outage, creating a larger, more unmanageable problem. Insulators located up high and out of reach. Since it's difficult to inspect, it's also a challenge to diagnose a problem, the failing component could be inside of the insulator, making it harder to get an accurate temperature measurement from a distance. 


\section{Journal of Student Research}

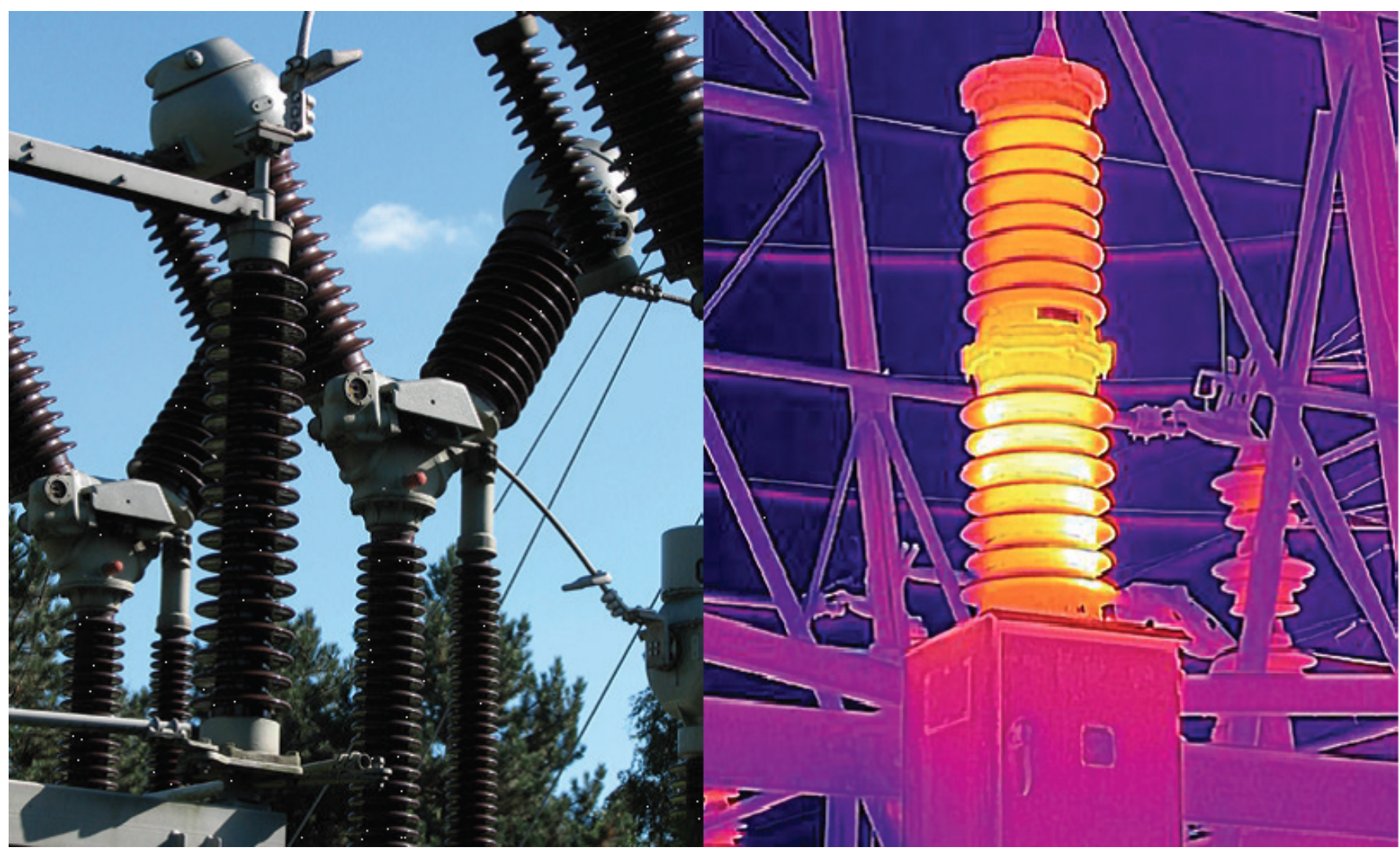

Figure 4. Insulator inspections using IR camera.

\section{(ii) Inspect SF6 Circuit Breakers}

Always Times new roman 9 pt as a font size. This section should be divided with subheadings.

Footnotes should not be used and will be transferred to the text. Always Times new roman 9 pt as a font size. This section should be divided with subheadings. Footnotes should not be used and will be transferred to the text. Always Times new roman $9 \mathrm{pt}$ as a font size. This section should be divided with subheadings. Footnotes should not be used and will be transferred to the text. Always Times new roman $9 \mathrm{pt}$ as a font size. This section should be divided with subheadings. Footnotes should not be used and will be transferred to the text. 


\section{Journal of Student Research}

Fourth Middle East College Student Research Conference, Muscat, Sultanate of Oman

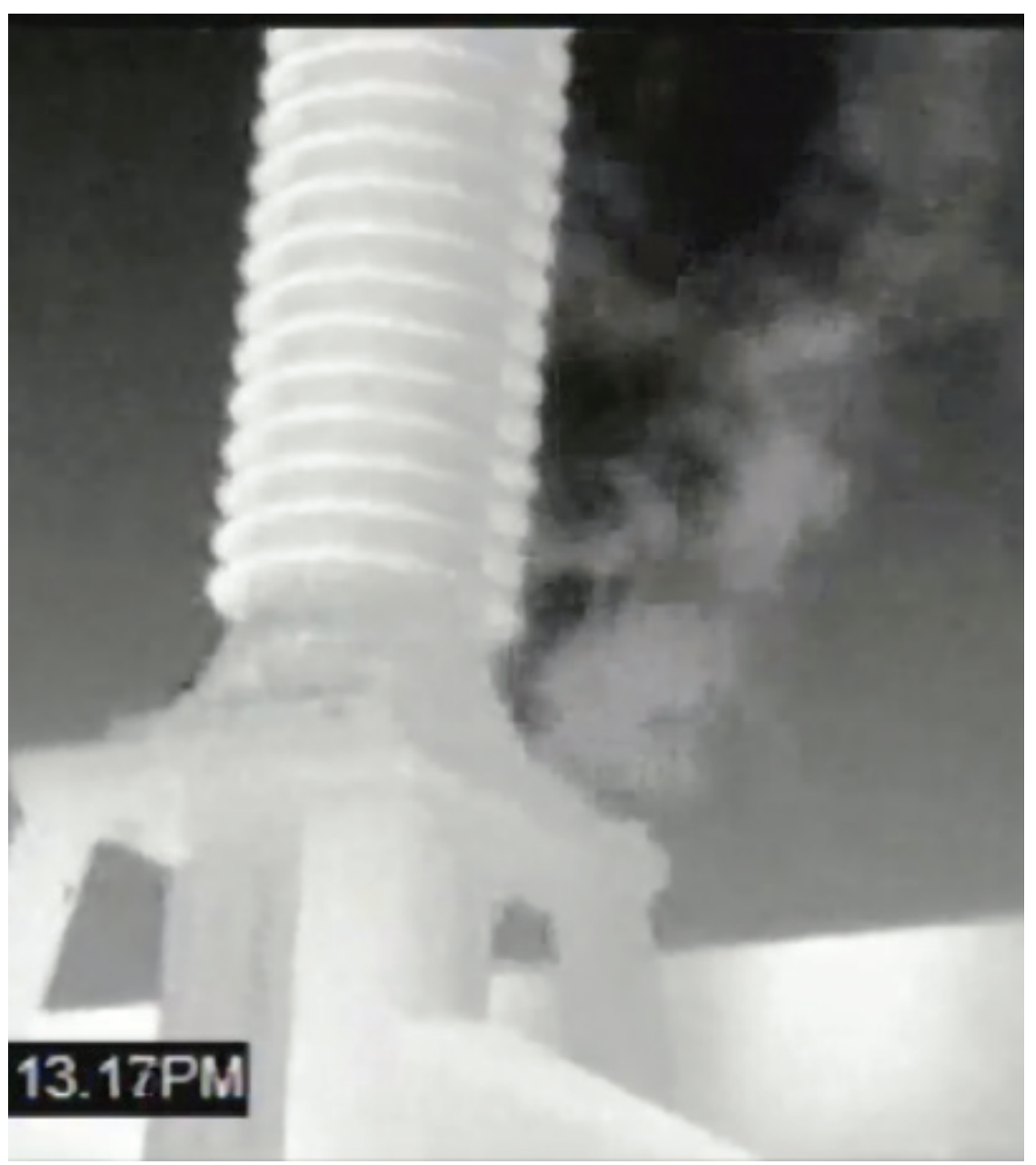

Figure 5. SF6 Circuit Breakers using IR camera

There's a gas leak in a SF6 breaker, it's crucial to locate and fix it immediately to minimize downtime and revenue loss. It's not always possible to come into close contact with the breaker to inspect it. The longer a leak is left unrepaired, the more revenue lost, and the greater the carbon footprint on the environment.

(iii) Connections in Electrical Transmission Table 1. 


\section{Journal of Student Research}

Fourth Middle East College Student Research Conference, Muscat, Sultanate of Oman

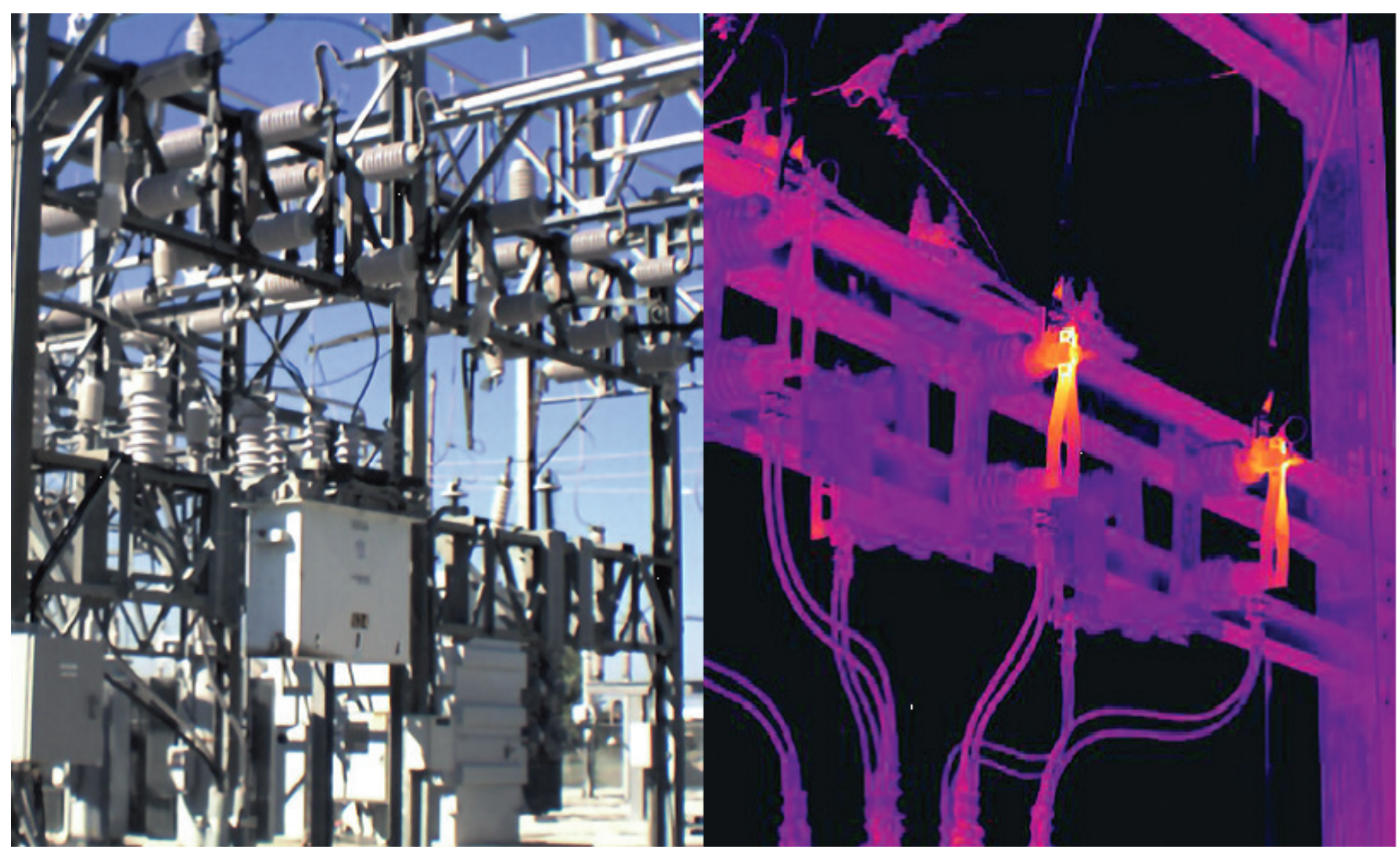

Figure 6. Connections in Transmission using IR camera

If an electrical connection isn't working properly, system may not operate efficiently or safely. It's important to regularly inspect every connection to ensure that they are in working order, but this can be a challenge. Every system has a lot of small connections, and they are often located high up out of reach.

(iv) Load Tap Changers (LTC) 


\section{Journal of Student Research}

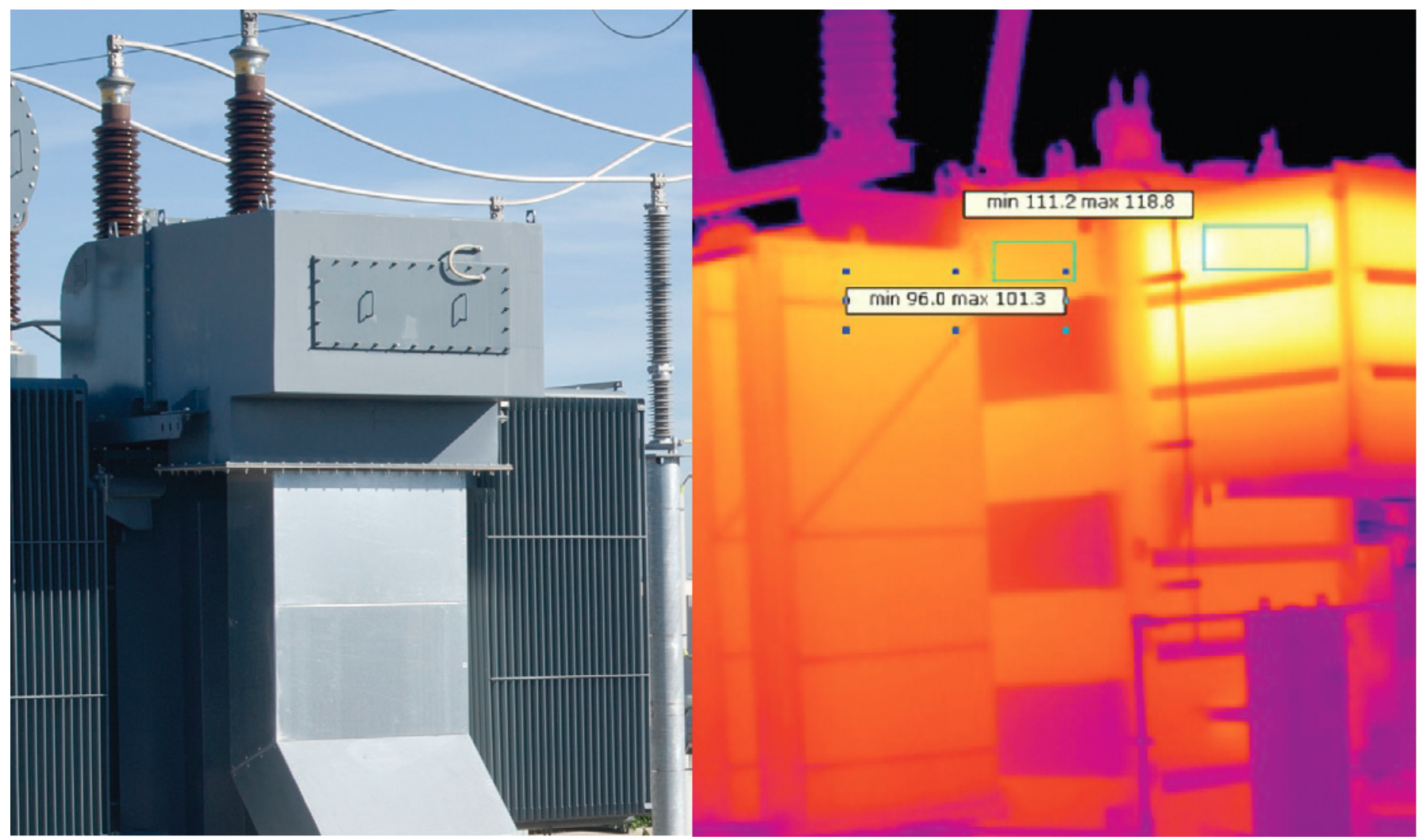

Figure 7. LTC inspections using IR camera.

If an LTC fails, the entire transformer will shut down. It causes additional expenses to expedite repair. This outage will adversely affect numerous distribution circuits and the remaining power grid due to the need to reroute the load to supply the affected circuits. Regularly assessing the health of LTCs and catching problems before a failure occurs is important to prevent downtime and minimize the cost of repairs.

\section{Corona Imaging of Equipment}

\section{(i) Degradation of Polymer Insulators}




\section{Journal of Student Research}

Fourth Middle East College Student Research Conference, Muscat, Sultanate of Oman

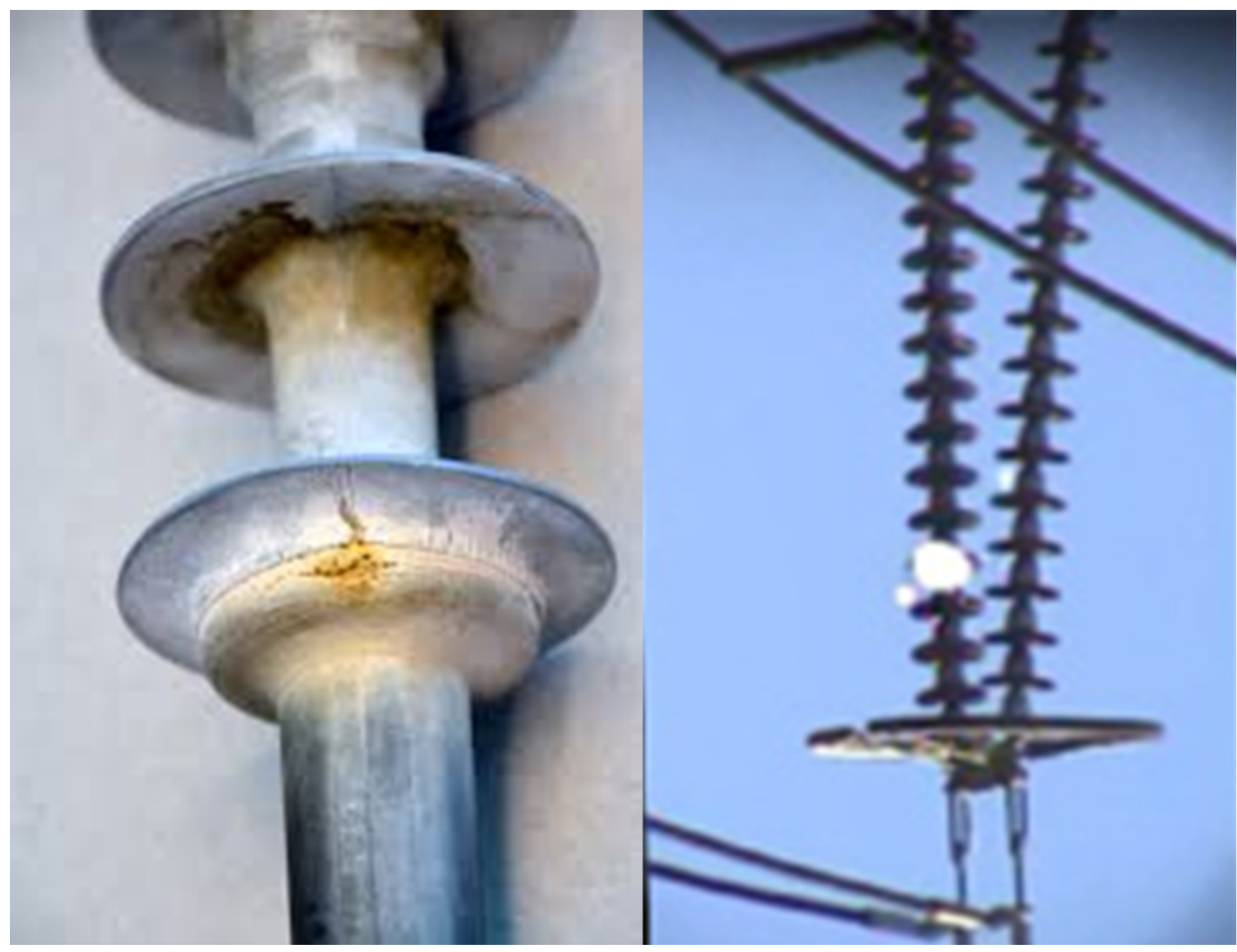

Figure 8. Degradation Insulators using corona camera.

There is a slow but progressive degradation of the polymeric insulator cover compound. This is due to open-atmosphere aging, where UV radiations from sunlight and electrical discharge adversely affect the matrix polymer. Other factors such as sandstorm, acid rain, and bird pecking.

\section{(ii) RFI, TVI and audio noise sources}




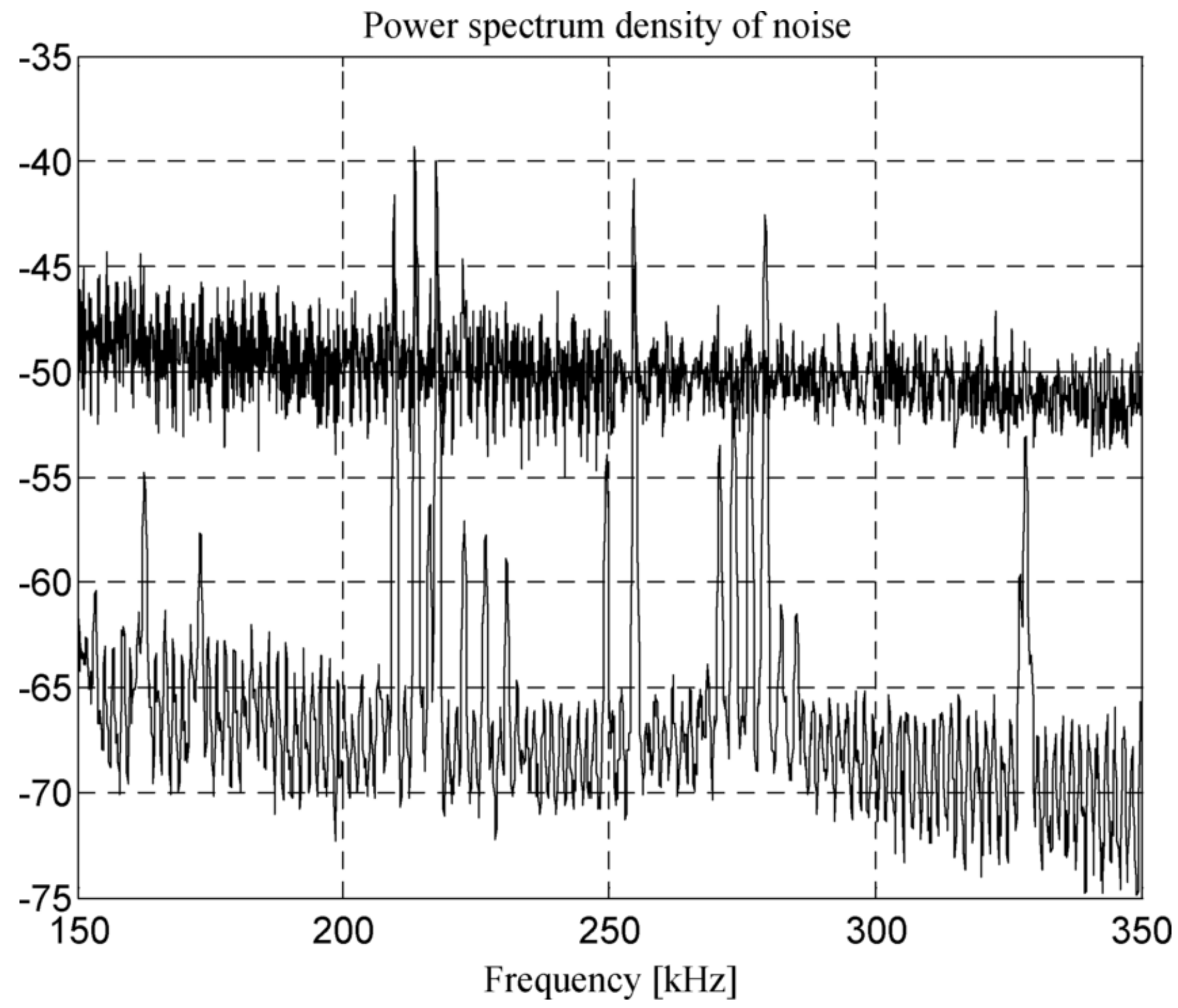

Figure 9. Communication Interference.

Power-line noise can interfere with radio communications and broadcasting. Essentially, the powerlines or associated hardware improperly generate unwanted radio signals that override or compete with desired radio signals.

\section{(iii) Wrong design and improper installation}

Electrical design of composite insulators should not be made looking solely at flashover performance during short-term tests. Rather, it must be based on risk of surface degradation from partial discharges which, over the long term can lead to tracking, erosion and eventual failure. Indeed, this is critical since composite insulators are vulnerable to damage should there be continuous partial discharges and arcing activity on or near their surfaces. 


\section{Journal of Student Research}

Fourth Middle East College Student Research Conference, Muscat, Sultanate of Oman

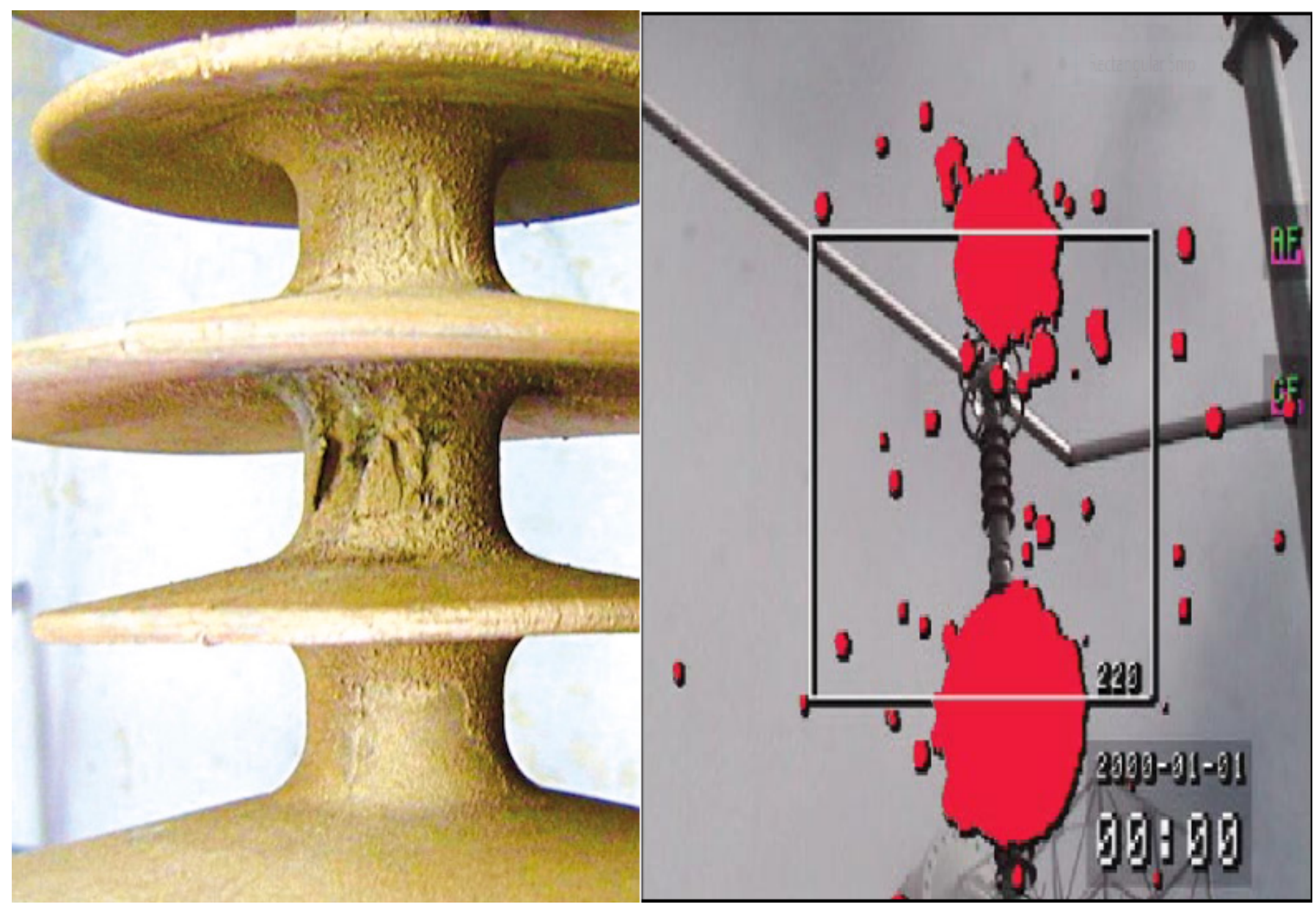

Figure 10. Improper installation of Insulator.

(iv) Contamination due to dust, Cracked porcelain Insulators

Porcelain bushings should be regularly checked for cracks and/or contamination. If the bushing is damaged or heavily contaminated, leakage current will become excessive, sometimes appearing as carbon tracking, or "treeing", on the bushing surface. Flashovers may occur if the bushings are not cleaned periodically.
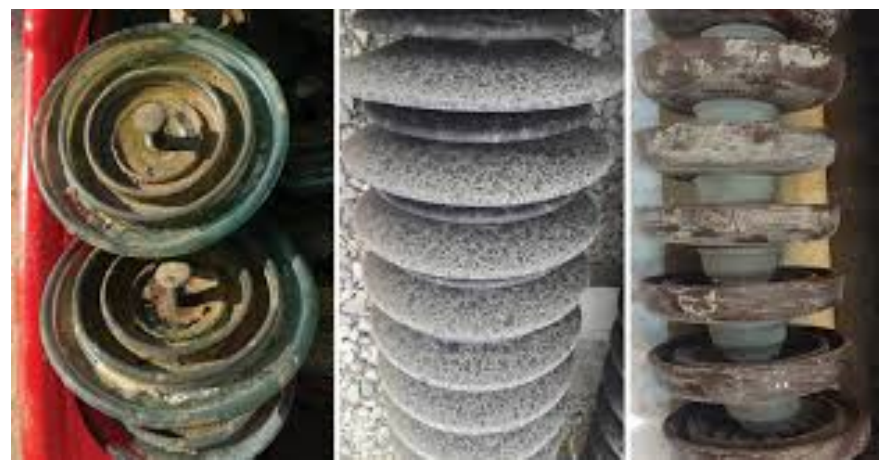

Figure 11. Cracked porcelain Insulators.

\section{(v) Rust on Caps and Pins of an Insulators}

Phenomena linked to corrosion of metal parts to affect the electrical resistance due to the formation of a deposit of rust on the insulating surface. To cause the breakage of the dielectric due 
to the expansion of the pin corroded. This phenomenon is specific for porcelain cap and pin insulators.

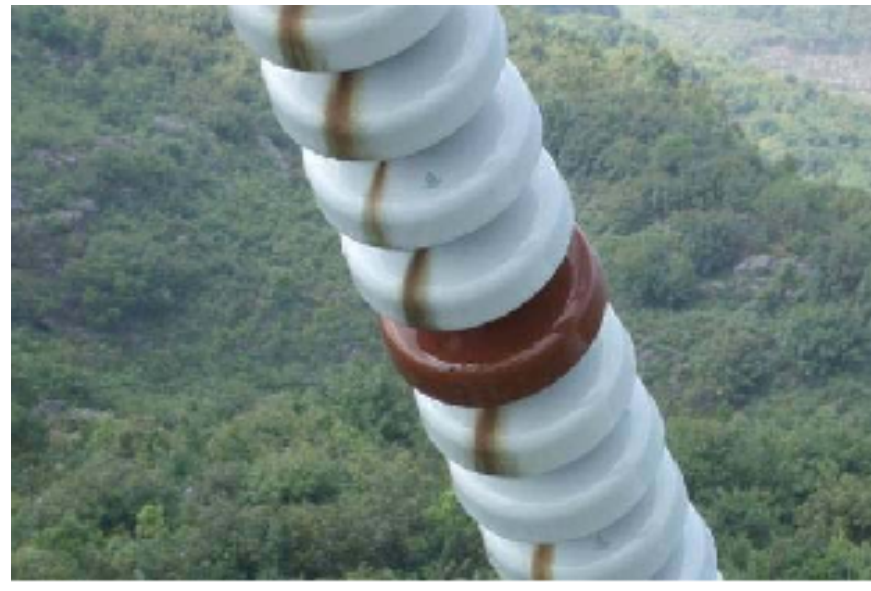

\section{a Corroded V-string insulators}

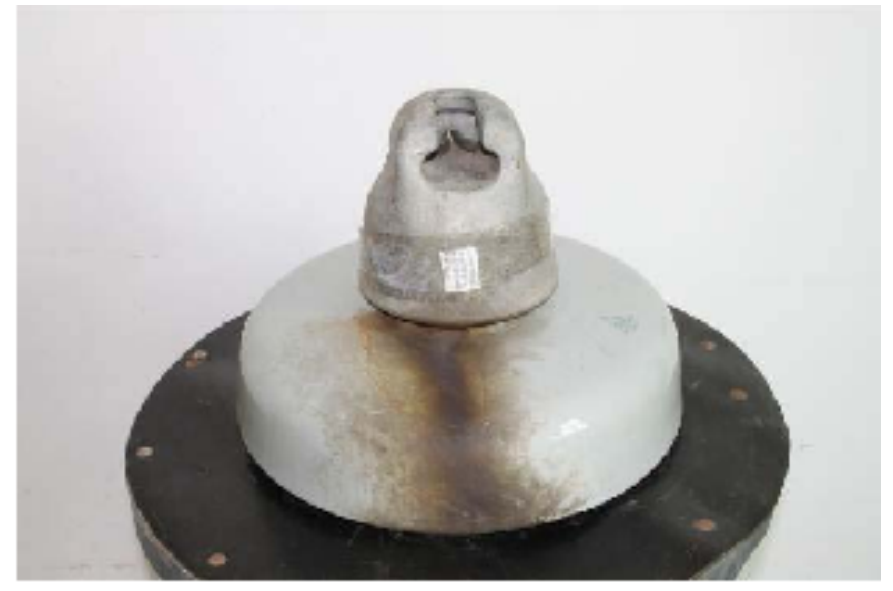

b Rust on the insulator surface Figure 1. Corrosion of insulators' iron cans.

Figure 12. Rust on Caps and Pins of an Insulators.

\section{(v) Discussion}

\section{(i) Thermal Imaging:}

Based on the image taken at the different equipment in the power system the thermal defects can be classified and the possible precaution as follows.

\begin{tabular}{|l|l|l|}
\hline General Defects & Serious Defects & Dangerous defects \\
\hline The range is10 200C. & The range 200C and 400C & exceeds 400C, \\
\hline attention is required & Defects shall be strictly monitored & maintenance carried out immediately \\
\hline & & \\
\hline
\end{tabular}

Table 2. Thermal faults with temperate difference and classification

\section{(ii) Corona Imaging:}

Based on the image taken at the different equipment in the power system the corona can be classified, and the possible precaution taken to avoid as follows.

\begin{tabular}{|l|l|l|}
\hline Initial Corona & Stable Corona & Glow Discharge \\
\hline less than 5000 photon/s & Partial discharge 5000 10000 & more than10000 photon/s \\
\hline Common defect & Serious defect & Crisis defect \\
\hline & & \\
\hline
\end{tabular}

Table 3. Corona faults and classification

\section{Conclusion}

By taking thermal images and UV images at regular intervals in network primary substation of Distribution will protect the power system equipment and reduces the outage of power. Thermal images mainly guide the situation of equipment considering the overheating and associated 


\section{Journal of Student Research}

Fourth Middle East College Student Research Conference, Muscat, Sultanate of Oman

problems. Which gives the exact monitoring pertaining to all power system equipment without interrupting the system. The advancement of technology not only protects the system but also saves revenue losses.

\section{Acknowledgements}

Our sincere gratitude and acknowledgements to Engineers of condition monitoring section of Majan Electricity Distribution company of Oman for they kind support and valueble time spending with us for taking the images at the primary distribution substation

\section{References}

Jianyong Ai (2015). “Detecting Partial Discharge of Polluted insulators Based on Ultraviolet Imaging"11 th International Conference on the Properties and Applications of Dielectric Materials.

I. Y. Shurrab (2012), "Partial Discharge On-Line Monitoring of Outdoor insulators". IEEE Symposium on Electrical Insulation (ISEI), pp: 391 - 394.

H. Li, R. Dai, M. Li (2011). "Insulator ultraviolet discharge feature ext raction based on level set". IEEE International Conference on Electrical and Control Engineering.

N. Maistry (2017).'”The world's first radiometric technology camera platform in Both the UV and IR spectrums to quantify power line faults".8th South African reginal Conference on electricity supply to Africa and developing economies -Challenges and opportunities Technology solutions and innovations for developing Economies.

R.Stolper and E. Cox,(2015) "The calibration and quantification of corona discharges on high voltage electrical equipment, using a corona camera.," in INMR, Germany.

Zhenyu Li(2016). Effects of Different Factors on Electrical Equipment UV Corona Discharge Detection, Article energies.

Han, S.; Hao, R.; Lee, J.(2009)." Inspection of insulators on high-voltage power transmission lines". IEEE Trans.Power Delivery. 24, 2319-2327.

Siyuan He (2015)," Detection and Fault Diagnosis of Power Transmission Line in Infrared Image". The 5th Annual IEEE International Conference on Cyber Technology in Automation, Control and Intelligent Systems June 8-12, Shenyang, China.

W. F. Zhang, X. Y. Peng, Y. M. Chen (2014), "Intelligent diagnostic techniques of abnormal heat defect in transmission lines based on unmanned helicopter infrared video," Power System Technology, vol. 38, No. 5,pp. 1334-1338.

W. H. Zhang, S. J. Yan, L. J. Jin(2012), "Infrared fault diagnosis of insulator based on multiinformation," Journal of system simulation, vol. 24, No.9, pp. 1810-1813. 